\title{
REVIEW
}

\section{Acronyms, abbreviations and initialisms}

\author{
D.A. BLOOM \\ University of Michigan, Ann Arbor, Michigan, USA
}

\section{Introduction}

'We, however, for our part, are convinced that the chief merit of language is clearness, and we know that nothing detracts so much from this as do unfamiliar terms; accordingly we employ those terms which the bulk of people are accustomed to use ...' Galen [1].

Medical writing has incorporated many changes to help compress ever more words onto paper and electronic pages. Initialisms and their pronounceable variant, the acronym, are favoured increasingly in these media, often at the price of clarity. Urologists, like all participants in any community of practice (in business parlance [2]), use language specific to their work which facilitates communication and helps define the community. Unique acronyms and other abbreviations are features of communal terminology and in urology no term has better depicted the speciality throughout much of the 20th century than 'TURP'. This and many other abbreviations/acronyms have transformed all forms of medical communication. Curiously, there seem to be no rules for abbreviated neologisms; anyone is at liberty to create one as the need or desire arises, but the marketplace of medical dialogue and discourse determines their durability and value. Whereas each medical speciality, just as any community of practice, has its distinct set of abbreviations, a more general set is accepted by most clinicians at large. However, abbreviated terminology contributes to the sense of jargon held by a layman or other outsider who lacks the appropriate Rosetta stone to decipher the language (Fig. 1).

\section{Language, phonemes and graphemes}

Language converts human imagination to reality, making human culture and science possible. Of the eight critical transitions in life on Earth, language is the most recent. Defining 'life' as an entity with the properties of multiplication, variation and heredity, Szathmary and

Accepted for publication 6 April 2000
Smith [3] drew a parallel between the genetic code and language:

'We believe it to be true that all systems of unlimited heredity will turn out to be modular. The statement is true not only of the genetic system based on DNA but also of the only other natural system of unlimited heredity known to us, human language. This is a system in which a small number of unit sounds (phonemes, roughly corresponding to the sounds indicated by the letters of the alphabet) can be strung together in different orders to express an infinitely large number of different meanings.'

The increasing complexity of life and human knowledge placed increasing demands on language, which responded to those demands. Of the $\approx 4000$ languages that serve the needs of the 6 billion people on this planet, English is presently the most pervasive in commerce and science. Alphabetic systems like English use 20-30 symbols (graphemes) and these are directly related to the sounds of language (phonemes) such that the system is adaptable and economic [4]. The English alphabet of only 26 characters has produced more than a half a million individual words, the most in any language. In contrast, there are well over 2000 traditional Chinese characters, allowing great diversity in expression, yet demanding a vast knowledge-base for skilled manipulation. These graphemes are not directly phonetic; each character symbolizes an idea and not a sound. Japanese, similarly logographic rather than alphabetic, relies on 1850 characters prescribed by the Ministry of Education as essential for everyday use. Children in the first 6 years of elementary school are taught 881 characters [4]. In these eastern languages, graphemes developed from ideographs to represent parts of words or entire words, with no direct linkage of a sound to the word; thus phoneme and grapheme are not closely linked. Scientific and technical English freely use several logographic characters with the alphabetic, e.g. signs for infinity $(\infty)$, plus $(+)$, percentage $(\%)$, equality $(=)$, and many others. Computer language and programming have greatly expanded this inclusion. The Rosetta stone of the brain translates the symbol (a logographic grapheme) into a useful phoneme. 


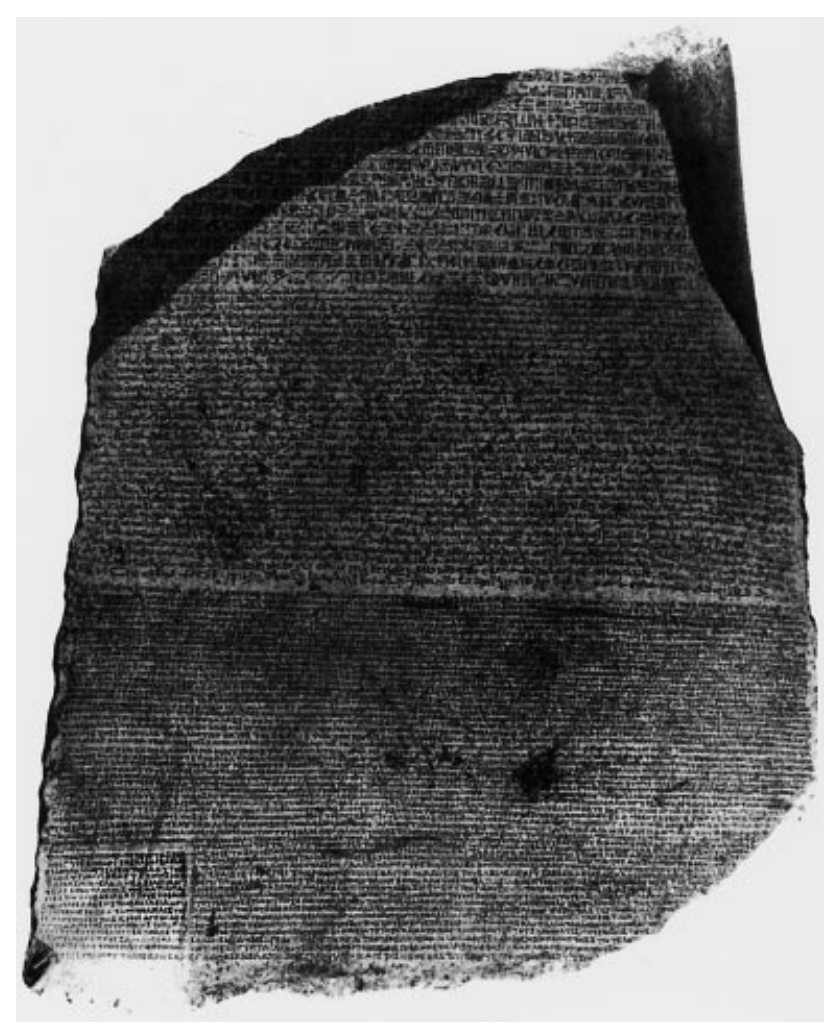

Fig. 1. The Rosetta Stone: a $114 \times 72 \mathrm{~cm}$ black basalt stone carved with three different scripts (hieroglyphic, demotic and Greek) of identical text commemorating the accession of Ptolemy V Epiphanes (205-180 всE) to the royal throne in Egypt. This stone, discovered in 1799 by Napoleon's expeditionary forces, allowed the hieroglyphic and demotic (everyday language of the time and place) to be deciphered and translated into alphabetic Greek. Courtesy, British Museum, London.

\section{Abbreviation}

As human culture diversified, words became more numerous and more complex. An early bureaucratic European empire, that of the Romans, soon discovered that when space and time were limited, long inscriptions could be more easily accommodated on parchment (or laboriously chiselled in stone) if the common words were abbreviated (Fig. 2a). Perhaps laziness also played a part, as even when space was not limited, the same abbreviations were used (Fig. 2b). As the Latin language and culture formed the basic tools for European technology and science (including most medical terminology) the habit was not lost.

Subsequent scientific innovation and communication further stretched the vocabulary. The binomial classification introduced by the Swedish naturalist Linnaeus (1707-1778) provided a new opportunity for neologisms. In this durable operational classification of the five kingdoms of life on earth, the first word, once introduced in conversation or writing, is usually abbreviated. For example, the $>4000$ known bacteria are usually described by abbreviating the genus name (as in E. coli). The periodic table of elements is best visualized as the elemental symbols and chemists invariably use them in preference to the whole words. The nomenclature of biology, chemistry, physics and medicine expands daily, far more quickly than dictionaries are edited. Scientific and technical dictionaries now rival traditional vocabulary dictionaries in size [5-7].

Although modern language favours simplicity, many new words are long, cumbersome and hard on the ear. Word simplification, i.e. abbreviation, can take several forms.

- Clipping, e.g. ad for advertisement

- Titular contraction, as in Mr, Dr or St

- First letter initialism, e.g. BPH, TUR, NPO, RSVP

- Opening letter initialism, e.g. Ca, HeLa

- Syllabic initialism, e.g. modem (modulator-demodulator)

- Combination initialism, e.g. ad inf (ad infinitum), email, CaP

- Acronym, e.g. TURP, radar

Clipping applies equally to spoken and written words; titular contraction applies to the written word and although contracted in print, these titles are automatically expanded or pronounced in their complete forms when read or spoken. Interestingly, Ms. ('miz') is a contraction with no source, an artificial abbreviation with no parental expanded form. Abbreviation by initialism can be applied to groups of words by substituting initial letters for the individual words. This practice goes back to its Latin origin, with 'i.e.' (id est, that is to say), q.e.d. (quod erat demonstrandum, that was to be proved), and, e.g. (exempli gratia, for example). Dirckxx [8] discusses several variants of initialism. The most common form of initialism simply replaces the entire word in a phrase with the first letter. Instead of periods (full stops) between the letters, the initialism can be confluent and capitalized. Thus 'atherosclerotic heart disease' becomes ASHD, or 'white blood cell' WBC. Yet another variant takes the initial letters of distinct syllables of the word, such as ECG for electrocardiogram. Common medical initialisms are legion and the BJU International provides an extensive list of examples at the end of every issue. Some governmental initialisms are now intrinsic parts of medical language, such as FDA (Food and Drug Administration of the US Department of Health and Human Services) or NHS (the UK National Health Service).

The general public may not recognize most abbreviations, but certainly most laymen understand 
DNA, RNA and AIDS. Some initialisms have been transmuted into verbs, e.g. have you RSVP'd yet? However, clarity is at risk not only from technical terminology, as Galen observed nearly 2000 years ago, but also from the ploy of abbreviation. Garner [9] strikes hard at the false idol of 'initialese':

'One of the most irritating types of pedantry in modern writing is the overuse of abbreviations, especially abbreviated names... many writers - especially technical writers ... allow abbreviated terms to proliferate, and their prose quickly becomes a hybrid-English system of hieroglyphs requiring the reader to refer constantly to the original uses of terms to grasp the meaning. This kind of writing might be thought more scholarly than ordinary straightforward prose. It isn't. Rather, it's tiresome and inconsiderate writing; it betrays the writer's thoughtlessness toward the reader and a puerile fascination with the insubstantial trappings of scholarship'.

Garner also warns about redundant initialisms, e.g. PIN number, when PIN is already defined as 'number'. The best urological example of this is 'IPSS score'.

Gleick [10] suggests that the store of words is now being exhausted, in an extension of the 'law of small numbers': 'there aren't enough small numbers to meet the many demands made of them.' Merging the concern about confusion in the shortage of brand names with the ambiguity of initialism, he writes:

'The domain of drug names is densely overcrowded, and the density carries particular dangers because confusion can be deadly. Is Rezulin the new insulin enhancer or the old antiacne medication? Is Dynacin the antibiotic and Dynacirc the antihypertensive, or is it the other way around? The package designers may wish to use NS for their nasal spray; will they know that doctors also use the term as shorthand for normal saline'.

Twenty-first century language will change to reflect the demands of society and science. Not only will the strong law of small numbers be tested in speech and writing, but also the rules of punctuation, grammar and capitalization will be challenged as electronic communication supplants pen and paper. The informality of email has led to a proliferation of initialisms, e.g. WRT (with respect to) and BFN (bye for now).

\section{The rise of the acronym}

The condensation of a word or phrase into a pronounceable initialism (acronym) seems to be a fairly recent invention, identified as being American. An acronym is a nuance of word-group abbreviation, wherein the word group (usually a single entity or noun, but sometimes a verb) is pronounceable. The neologism is usually operationally more valuable (and ideally, easier on the ear and tongue) than the parent word group. The line between simple initialism and pronounceable acronym can be indistinct (e.g. ELISA) although general usage favours the case for simple initialism. Fowler [11] labelled abbreviations 'curtailed words' and noted the special circumstances of acronyms.

'Another way of forming curtailed words is to combine initial letters, a method now so popular, especially in America, that a word 'acronym' has been coined for it. The first world war produced a few; Anzac (Australian and New Zealand Army Corps), Dora (Defence of the Realm Act), Wrens (Women's Royal Naval Service)...'

Sir Ernest Gowers, one of the great authorities on English literary style, revised Fowler's Modern English Usage. Gowers, the son of a physician, credited his critical eye and ear for language to his father [12]:

'Some 70 years ago a promising young neurologist made a discovery that necessitated the addition of a new word to the English vocabulary. He insisted that this should be knee-jerk, and knee-jerk it has remained, in spite of the efforts of patellar reflex to dislodge it. He was my father; so perhaps I have inherited a prejudice in favour of home-made words.'

The father was Sir William Richard Gowers (1845-1915). Implicit in Fowler's interpretation of the acronym is the pronounceability as a word, although not all authorities have demanded this test. The Council of Biology Editors Style Manual in 1978 [13] stated: 'No distinction is made between abbreviations and acronyms in this manual, and they are collectively termed abbreviations.'

The practice of acronymology is far older than its representation by a word. Students have long made mnemonic initialisms to help retain tedious information. Thus the six critical elements of life, referring back to the periodic table, are CHNOPS, which, if pronounced as 'chin-ups', qualifies it as an acronym. To locate the femoral artery generations of medical students have depended on NAVEL, going from lateral to medial under the right inguinal ligament: nerve, artery, vein, empty space, and lymphatic. The corporate world and scientists were doing this sort of thing early in the 20th century, but the first acknowledgement of this practice as a general tool in language with the neologism acronym was 1943 [14]. Defining examples in the Oxford English Dictionary include MASH (mobile army surgical hospital), Nabisco (National Biscuit Company) and NATO (North Atlantic Treaty Organization). The Second World War era provided several useful and often colourful acronyms, including SNAFU (situation normal, all fouled up), RADAR (radio detecting and ranging), and SONAR (sound navigation range). With their incorporation into everyday speech, radar, sonar and other terms have become so commonplace that they have lost their capitalization, as if they have become less overtly acronyms.

Acronyms are firmly fixed in speech and writing, providing great value in modern communication. 

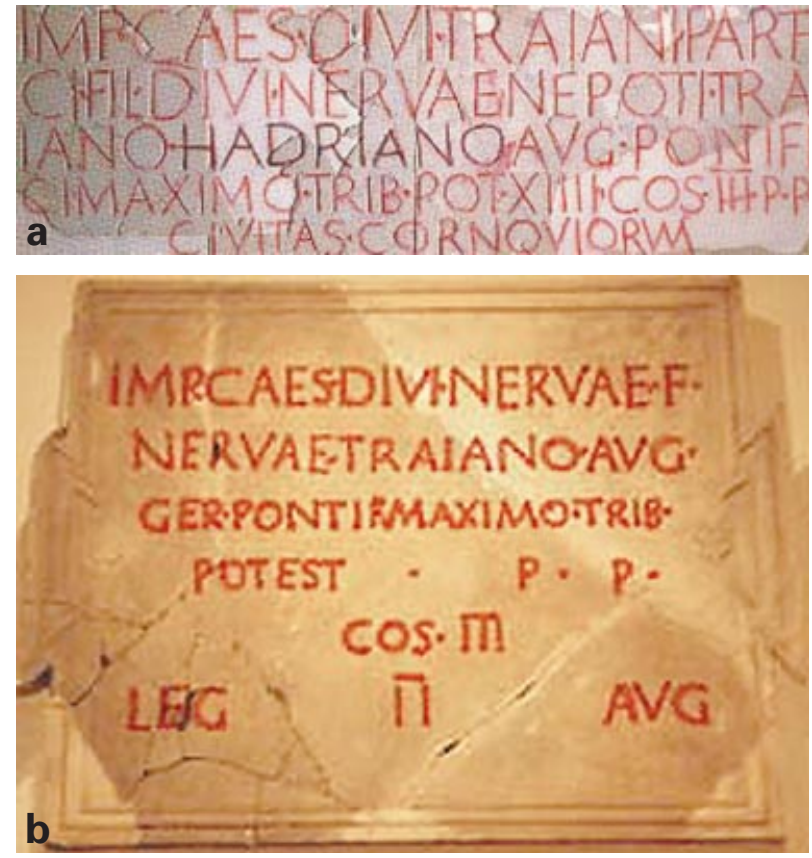

Fig. 2. (A) An example of a Romano-British inscription showing that the city of the Cornovii (Civitas Cornoviorum, now Wroxeter, near Shrewsbury) dedicated the Forum building to the Emperor Hadrian. The text reads: IMP[eratori] CAES[ari] TRAIANO HADRIANO AUGUSTO DIVI TRAIANI PARTHICI FIL[io] DIVI NERVAE NEPOTI PONTIFICI MAXIMO TRIB[unicia] POT[estate] P[atri] P[atriae] COS III. CIVITAS CORNOVIORUMand is translated as: 'To the Emperor Caesar Trajan Hadrian Augustus the Divine Trajan Parthicus' son, the Divine Nerva's grandson. Trajan Hadrian Augustus: Chief Priest, holder of Tribunician Power 9 (years): Father of his Country. In the 3rd year of his consulship. City of the Cornovii'. (B) An inscription from Caerleon (near Newport in South Wales, known to the Romans as Isca Silorum). It was originally on the wall of a building which the Second Legion Augusta dedicated to the Emperor Trajan. The text reads: IMP[eratori] CAES[ari] DIVI NERVAE F[ilio] NERVAE TRAIANO AUGUSTO GERMANICO PONTIFICI MAXIMO TRIB[unicia] POT[estate] P[atri] P[atriae] COS III LEG II AUGand is translated as: 'To the Emperor Caesar Nerva Trajan Augustus Germanicus the Divine Nerva's son: Chief Priest: holder of Tribunician Power: Father of his Country in the 3rd year of his consulship. Second Legion Augusta'. Both pictures are used with permission, and with thanks to Pyrrha[http://www.pyrrha.demon.co.uk/index.html].

However, there is widespread evidence of overuse in technical writing and it may be wise to follow some simple rules for acronymology:

- An acronym is at least three letters.

- The word must be easily pronounceable.

- It must simplify communication.

- An acronym should have utility beyond a single paper/ report.

- Spell out the complete term at first usage.

- More than one new neologism or novel abbreviation per paper burdens the reader.
- Do not put the reader in the position of having to refer back to a key of novel abbreviations. It is preferable to spell out most repetitive phrases.

\section{Urological acronyms and other initialisms}

Abbreviation of medical language was rare in genitourinary textbooks or journals 100 years ago. Urology prose in the early 20th century rarely invoked short and sweet terminology. The first volume of the Journal of Urology, published in 1917, includes scarcely any word simplifications apart from the abbreviations of binomial names for bacteria, chemical element symbols, and expected contractions (cc for cubic centimetres, mgm for milligrams, Fig. for figure, and others). There is the occasional contraction of phenolsulphonphthalein test to "phthalein test. Some logical simplifications are ignored, like percentage, blood urea nitrogen, blood pressure and specific gravity. In 1929, the first issue of the British Journal of Urology was similarly devoid of initialisms except for the very common abbreviations like mg, i.e., $\mathrm{lbs}$, fig, and the initialisms in the references. On some occasions even common initialisms were omitted in favour of the full word, such as bacillus, red cell count and milligrams.

Hinman's urology text of 1935 [15] has only the occasional abbreviation, such as KUB for kidneys, ureters, and bladder when describing a plain abdominal $\mathrm{X}$-ray. Hyperplasia of the prostate, intravenous pyelography and urinary tract infection are always spelled in full. Dodson's text in 1944 [16], typical for the era, used small standard abbreviations ( $\mathrm{Hb}, \mathrm{cc}$, No., Fig., $\mathrm{CO}_{2}$, and $\mathrm{m}$. for muscle), but included no urological abbreviations. Excretory urography, intravenous pyelography and transurethral resection were always spelled out completely. Urinary infections were never discussed generically (as in UTI), but were listed only by site in the index. Schmidt's Dictionary of Medical Slang in 1959 [17] is replete with sexual terminology, but abbreviations and initialisms are rare, except for terms such $\mathrm{Ab}$ for abortion, $\mathrm{BP}$ for blood pressure, or PM for post mortem. There is no mention of TURP or any related urological terms; indeed, of 6500 entries, there are barely 100 initialisms.

In 1950, volume 63 of the Journal of Urology contained eight articles dealing significantly with TURP, one used a TUR abbreviation, and even that was only in a table and not in the text [18]. In 1960, volume 88 of the Journal of Urology also included eight TUR-orientated papers; seven of these strictly used the full terminology and only one resorted to TUR (mentioned four times) [19]. In 1970, volume 104 of the Journal of Urology contained five such papers; one resorted to a TUR abbreviation only in 
figures, two only spelled out transurethral resection and two made extensive use of TUR and TURP (for a total of 34 uses) [20-24].

The first issue of Urology appeared in 1973 and abbreviation featured prominently in the first article, with six initialisms used 21 times. These terms reflect the emerging molecular biological emphasis in medicine; most of these were in one review article and included DNA, RNA and ACTH [25]. Even though TURP was then widely accepted in speech, the preference in print remained the complete phrase, occurring throughout volume 1 (in addition to 'prostatectomy') with no abbreviation or acronym. The first 10-year cumulative index for Urology (1973-82) contains only a single entry for TUR and another for TURP [26].

As from 1990, TUR and TURP were freely used in print, as shown in the British Journal of Urology Volume 66, which contains two articles specifically addressing that procedure. Hahn's paper [27] defines TURP in the abstract and then uses it nine times in the text and six times in tables. Additionally, 18 other abbreviations are apparent, including CVP (central venous pressure), RISA (radioiodinated serum albumin), $\mathrm{Hb}$ (haemoglobin), P (probability), NS (not significant), H-P (Hewlett Packard), and the commonplace $\mathrm{Na}$ (sodium) and $\mathrm{ml}$ (milliliters). The other paper [28] defers initialism in the title and abstract, but introduces TURP in the second sentence of text, and uses it three times later in the text and only once in a table. BPH is used three times and once in a table. Overall there were five technical initialisms (BPH, TURP, TO, EDTA, UICC) and 16 more general abbreviations.

In 1996, the British Journal of Urology introduced its version of the Rosetta stone, a table of abbreviations in each issue, with the instructions that the listed abbreviations did not require definition in the text. However, international conventions required that each abbreviation be defined in the abstract. The accompanying paper by Grange [29] offered a clear vision of the technical aspects of scientific writing that would have been quite agreeable to Galen. The Journal's general instructions on abbreviations are cogent: limit them and use them consistently.

By the end of the century the acronym and other abbreviations were in full display in the urological literature. The first issue of the Journal of Urology in 2000 is replete with abbreviations. Counting acronyms and other technical initialisms in the abstracts alone (excluding common abbreviations such as $\mathrm{cm}$ ) there are 47 different terms invoked 285 times. The most common were PSA (used 87 times) and BCG (30 times). Surprisingly less common were $\mathrm{BPH}$ (nine times) and IVP (once). One abstract used four initialisms 18 times; another included five new abbreviations 29 times. Some were seemingly newly minted for the paper, e.g. HxBCa, for 'patients with a history of bladder cancer' [30].

Some acronyms and initialisms fit the needs of the moment, to compress a paper or abstract, whereas others are destined for longevity. Overuse of abbreviations for the writer's convenience or for the constraints of word counts, generally obfuscates information. The ultimate connoisseur of style in the English language, Strunk, was sceptical of curtailed words, writing [31]:

'Many shortcuts are self defeating; they waste the reader's time instead of conserving it. The longest way around is usually the shortest way home, and the one truly reliable shortcut in writing is to choose words that are strong and sure-footed, to carry the reader on his way.'

The replacement of 'transurethral resection of the prostate' (which probably seemed a far bigger mouthful of words in 1940 than in 2000) with TURP (which is not only succinct, but also pronounceable) was a gift to communication. Whether or not technology will marginalize TURP remains to be seen. If so, it can only be hoped that the replacement therapy for BPH and the replacement acronym for TURP will be as good as the originals.

\section{References}

1 Galen C. On the Natural Faculties. Brock AJ (Transl). Cambridge, MA, London: Harvard University Press, 1916:3

2 Wenger EC, Snyder WM. Communities of practice: the organizational frontier. Harvard Business Review 2000; JanFeb: $139-45$

3 Szathmary E, Smith JM. The Origins of Life. Oxford: Oxford University Press, 1999: 9-19

4 Crystal D. The Cambridge Encyclopedia of Language Cambridge: Cambridge University Press, 1987: 85, 200

5 Parker SP. McGraw-Hill Concise Encyclopedia of Science and Technology. 4th edn. New York: McGraw-Hill, 1998

6 Anderson DM, Pugh MB, eds, Dorland's Medical Dictionary. 28th edn. Philadelphia: WB Saunders, 1994

7 Pugh MB, ed. Stedmans Medical Dictionary. 27th edn. Baltimore: Williams \& Wilkins, 2000

8 Dirckxx JH. The Language of Medicine. 2nd edn. New York: Praeger Publishers, 1983: 109

9 Garner BA. The Oxford Dictionary of American Usage and Style. Oxford: Oxford University Press, 2000: 2

10 Gleick J. Faster. The Acceleration of Just About Everything New York: Pantheon Books, 1999: 261-2

11 Fowler HWA. Dictionary of Modern Usage. 2nd edn. Revised by Sir Ernst Gowers. Oxford: Clarendon Press, 1968: 116

12 Strauss MB. Familiar Medical Quotations. Boston: Little Brown, 1968: 611

13 Huth EJ, Altman PL, Burgan MW et al. Council of Biology Editors Style Manual. Arlington, VA: Council of Biology Editors, Inc. 1978:114

14 Simpson JA, Weiner ESC. The Oxford English Dictionary. 2nd edn. Oxford: Clarendon Press, 1991:121 
15 Hinman F. The Principles and Practice of Urology. Philadelphia: WB Saunders Co., 1935: 647

16 Dodson AI. Urological Surgery. St. Louis: CV Mosby Co., 1944

17 Schmidt JE. Dictionary of Medical Slang. Springfield, IL: Charles C. Thomas, 1959

18 Schmidt SS, Hinman F. The effect of vasectomy upon the incidence of epididymitis after prostatectomy; an analysis of 810 operations. J Urol 1950; 63: 872-8

19 Cooner WH, Burros HM. Clinical evaluation of effect of premarin on bleeding during and following prostatic surgery. J Urol 1960; 83: 64-6

20 Ochsner MG, Burns E, Henry HH II. Incidence of retrograde ejaculation following bladder neck revision as a child. J Urol 1970; 104: 596-7

21 Marmar JL, Allen SD. The transurethral resection reaction secondary to intraperitoneal extravasation of irrigating solution. J Urol 1970; 104: 457-8

22 Reuter HJ. Electronic lithotripsy: transurethral treatment of bladder stones in 20 cases. J Urol 1970; 104: 834-8

23 Genster HG, Madsen PO. Urinary tract infections following transurethral prostatectomy: with special reference to the use of antimicrobials. J Urol 1970; 104: 163-8

24 Madsen PO, Knuth OE, Wagenknecht LV, Genster HG. Induction of diuresis following transurethral resection of the prostate. J Urol 1970; 104: 735-8

25 Amelar RD, Dubin L. Male infertility. Urology 1973; 1: 1-31

26 Anonymous. Ten-Year Cumulative Index, Volumes I-X/ January 1973-December 1982. Urology 1982; 167

27 Hahn RG. Fluid and electrolyte dynamics during development of the TURP syndrome. Br J Urol 1990; 66: 79-84

28 Lyth DR, Booth CM. Does ethamsylate reduce haemorrhage in transurethral prostatectomy? Br J Urol 1990; 66: 631-4

29 Grange RI. Technical editing. Br J Urol 1996; 77: 3-5

30 Lokeshwar VB, Obek C, Pham HT et al. Urinary hyaluronic acid and hyaluronidase markers for bladder cancer detection and evaluation of grade. J Urol 2000; 163: 348-56

31 Strunk W Jr. The Elements of Style. New York: Macmillan Company, 1959: 67

\section{Author}

D.A. Bloom, MD, Professor of Surgery, University of Michigan, Ann Arbor, 1500 East Medical Center Drive, Ann Arbor, Michigan 48109-0030, USA.

\section{Editorial comment}

The use of abbreviations, initialisms and acronyms is a constant source of concern to the BJU International. The current system using a List of Abbreviations (at the end of each issue) was devised knowing the problems with this format. There is an inevitable compromise among the aims of attempting to conserve space, avoiding repetition, and the resulting readability; there is an often unwelcome demand on the reader to refer to the list when reading the papers. Moreover, within the few years since devising the recommended list, there have been changes. Some terms are no longer as common as they were perceived to be and have been removed from the list, or are now almost unused (e.g. EMA, PHA), while others have been added as they have become more important in urology (e.g. TGF). Others have been left, although seldom used, because the expanded term is over-long (e.g. RFLP).

A further concern is the electronic delivery of the papers in the BJU International. Readers will be aware that most of the Case Reports are now only accessible on the relevant website, where the List of Abbreviations is not immediately available, as it is at the end of the paper journal. This poses an interesting dilemma; one original intention of using the List was to reduce the space (and costly paper) wasted in the frequent repetition of long and familiar terms. Is this still a requirement when no paper is involved? Or is this an example of laziness and habit, like Fig. 2b?

There are other aspects of the acronym or initialism which might be considered. The BJU International is currently translated into other languages (Spanish, Italian and Turkish). An eminently pronounceable or familiar acronym may become meaningless in another language - is transurethral resection of the prostate still TURP in Spanish? Or worse, are there common abbreviations which become offensive words in Turkish?

Bob Grange

Technical Editor, BJU International 